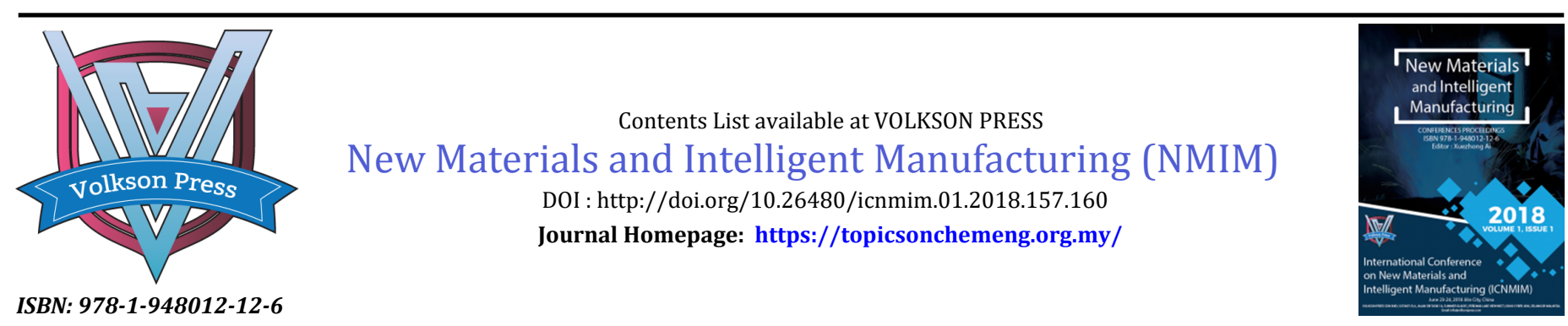

\title{
SYNTHESIS OF SULFUR-CONTAINING NITROGEN AND PHOSPHORUS FLAME RETARDANT AND ITS APPLICATION TO POLYACRYLONITRILE FIBER
}

\author{
Hao Feng-Ling, Song Chuan-Jie, Liu Qun \\ Jilin Institute of Chemical Technology, Ji Lin \\ *Corresponding Author Email: 835938176@qq.com, liuqun198707@163.com
}

This is an open access article distributed under the Creative Commons Attribution License, which permits unrestricted use, distribution, and reproduction in any medium, provided the original work is properly cited

\section{ARTICLE DETAILS}

Article History:

Received 26 June 2018 Accepted 2 July 2018 Available online 1 August 2018

\section{ABSTRACT}

Flame retardant ditrimethylolpropane diphosphothiourea (DDT) was synthesized by using ditrimethylolpropane(DTMP), phosphoryl chloride(POCl3) and thiourea as raw materials. Preparation of finishing agent with ethanol as solvent and used as a flame retardtant for polyacrylonitrile fiber. The effect of finishing agent solution concentration, curing temperature and curing time on flame retardancy, whiteness and breaking strength of polyacrylonitrile fiber was also discussed. The optimal synthesis conditions for DDT were determined: the finishing liquid concentration was $200 \mathrm{~g} / \mathrm{L}$ and baking $80^{\circ} \mathrm{C}$ for $3 \mathrm{~min}$. The results showed that the flame-retardant efficiency reached national standard B1 level and retained higher breaking strength and whiteness.

\section{KEYWORDS}

Thiourea, flame retardant, polyacrylonitrile fiber, synthesis process.

\section{INTRODUCTION}

Polyacrylonitrile fiber, also known as polyacrylonitrile fiber, was made of polyacrylonitrile or acrylonitrile over $85 \%$ of the copolymer. It has good elasticity, soft hand, good warmth retention, good dyeing, easy to dry, simple nursing, good weather resistance, mould resistance and chemical stability, so it was widely used [1]. As polyacrylonitrile fiber has an incomplete quasicrystal structure and was sensitive to heat, the thermal stability of polyacrylonitrile fiber was poor. In addition, thermal oxidation cracking in the air will produce the pyrogenation products of acrylonitrile, acetonitrile, ammonia and water, and combustible gases, and then promote the combustion [2]. The limit oxygen index (LOI) of polyacrylonitrile fiber was about $18 \%$, which was the lowest in synthetic fiber and was flammable fiber. It was generally considered that the LOI value was above $26 \%$ and has a certain flame retardancy. Therefore, it was of great significance to the study of the flame retardancy of acrylic fabric.

Among many kinds of flame retardants, halogen flame retardants have many advantages, such as good flame-retardant effect, less dosage, little impact on the mechanical properties of materials, etc. At present, most of the fire-retardant polyacrylonitrile fiber has been produced by the copolymerization of chlorinated monomers. The flame retardancy of nitrile chlorofibre, and its fabrics was good and the flame-retardant efficiency was lasting. However, the toxic hydrogen chloride gas will be produced during the severe burns, which endangers the health of the human body and pollutes the environment. Therefore, the flame retardant polya- crylonitrile fiber should develop to the halogen-free environment. The intumescent flame retardant (IFRs) of nitrogen and phosphorus was flame retarded by the synergistic effect of acid source, carbon source and gas source. It has the advantages of halogen-free, low smoke, low toxicity and non-corrosive gas [3]. It was an important study direction of halogen free flame retardant. More and more research and application have been obtained. In addition, through the introduction of silicon, boron, sulfur and other elements can significantly improve the flame retardancy of flame retardants [4-10].
Flame retardant ditrimethylolpropane diphosphothiourea (DDT) was synthesized by using ditrimethylolpropane (DTMP), phosphoryl chloride $\left(\mathrm{POCl}_{3}\right)$ and thiourea as raw materials. The finishing agent was prepared with ethanol as solvent, and the polyacrylonitrile fiber was subjected to flame-retardant finishing. The effects of finishing agent dosage, curing tem- perature and baking time on the flame-retardant efficiency, whiteness and breaking strength of polyacrylonitrile fiber were discussed, and the optimal synthesis conditions for DDT were determined.

\section{EXPERIMENTAL}

\subsection{Materials and Instruments}

Fabric material: $23.8 \times 43.5$ tex, $0.021 \mathrm{~g} / \mathrm{cm}^{2}, 440 / 10 \mathrm{~cm} \times 230 / 10 \mathrm{~cm}$, Acrylic twill.

Chemicals: Ditrimethylolpropane (DTMP) (industrial products,mass fraction $>99.0 \%$, Jihua Group Jilin Alliance of welfare Chemical Factory), Phosphoryl chloride $\left(\mathrm{POCl}_{3}\right.$ ) (analysis pure, mass fraction $>99.5 \%$, Tianjin Sailboat Chemical Reagent Technology Co., Ltd.), Thiourea (analysis pure, mass fraction $>99.0 \%$, Tianjin Yongda Chemical Reagent Co., Ltd.).

Main equipment:MU-504 Desktop padder (Beijing Textile Machinery EquiEquipment Co., Ltd.), DHG-9108A Baking oven (Shanghai Precision Instrument and Meter Co., Ltd.), WBS Whiteness instrument (Shanghai XinRui Instrument and Meter Co., Ltd.), YG-026T Electronic fabric strength machine (Wenzhou Fangyuan Instrument Co., Ltd.), LFY-601 Vertical woven fabric flame retardant performance tester (Shandong Textile Science Research Institute).

\subsection{Synthesis of flame retardants}

(1) $0.3 \mathrm{~mol}$ DTMP were added to a $250 \mathrm{~mL}$ glass flask equipped with a mechanical stirrer, thermometer sensor, and circumference condenser. Turn on the circumference condensate, stir slowly, and $0.9 \mathrm{~mol}$ of phosphorus oxychloride were added to the glass flask using a constant pressure dropping funnel (About $85 \mathrm{~mL}$ ), slower to faster, and the control was completed in about 30 minutes. The temperature was raised to $60^{\circ} \mathrm{C}$, and the reaction was carried out at a constant temperature for 4 hours (the reaction time was measured from the start of dropwise addition of 
phosphoryl chloride), a viscous, light -yellow liquid was optained, that was intermediate (I) ditrimethylolpropane diphosphoryl chloride(DDC). Hydrochloric acid was withdrawn in time during the reaction and was absorbed by lye. The vacuum pump was turned on once every $30 \mathrm{~min}, 1 \sim 3$ $\mathrm{min} /$ time.

(2)In the ice water bath, $30 \mathrm{~mL}$ of distilled water was added dropwise to the intermediate (I), control the dropping rate to prevent the reaction system from heating up too quickly. After the dropwise addition was completed, the temperature was raised to $70^{\circ} \mathrm{C}$, and hydrolyzed for 1.5 to $2.0 \mathrm{~h}$ to yield a brown yellow hydrolysate (II) Ditri-methylolpropane bisphosphate (DTB).

(3)The thiourea was added to the hydrolysate (II), stirring up the temperature and con-stant temperature reaction, the light-yellow viscous liquid was obtained. After the heat was taken out, the white or light-yellow viscous substance by static cooling, that was the target product ditrimethylolpropane diphosphothiourea (DDT) (III).

\subsection{Process of flame retardant finish}

Finishing agent formula: Ethanol was a solvent, and the finishing agent dosage was $50 \sim 300 \mathrm{~g} / \mathrm{L}$. Process: dip finishing (one-dip-one-nip), $50^{\circ} \mathrm{C}$, $20 \mathrm{~min}$, rolling residual rate $(60 \% \sim 70 \%) \rightarrow$ Pre-drying $\left(80^{\circ} \mathrm{C}\right.$, 3 min, $) \rightarrow$ baking $\left(80 \sim 120^{\circ} \mathrm{C}, 0 \sim 8 \mathrm{~min}\right) \rightarrow$ finished.

\subsection{Analysis testing}

\subsubsection{Flame retardancy}

The ethanol was added to $100 \mathrm{~g}$ flame retardant and fixed to $400 \mathrm{~mL}$, stirring evenly, that was, the dosage of finishing agent was $250 \mathrm{~g} / \mathrm{L}$. The polyacrylonitrile fiber cut to dimensions of $30 \mathrm{~cm} \times 9 \mathrm{~cm}$ was put into a working bath, $20 \mathrm{~min}$ impregnated at $50^{\circ} \mathrm{C}$, one dip and one rolling, a wet pick up of $60 \% \sim 70 \%$, and the treated polyacrylonitrile fiber were baking at $80^{\circ} \mathrm{C}$ for $5 \mathrm{~min}$. The flame-retardant cloth was obtained.

The cloth clamp was used to fix the fabric in the combustion box, the gas tank was ventilated to the combustion port, the valve was opened, the power supply was opened, the ignition key was opened, and the flame height was stabilized in the position of the baffle above the burner, after the ignition was successful. After the preparation was ready, press the start key to start the timing, the flame controller automatically moves to the bottom of the sample to burn $3 \mathrm{~s}$ vertically, then returns to the place, and records the continuous burning time and the time of the smoldering of the sample cloth, taking down the polyacrylonitrile fibers by measurement of the burning length, the width of the middle and the bottom width.

\subsubsection{Whiteness Test}

Reference to standard GB/T8424.2-2001《Textiles-Tests for color fastness-Instrumental ass- essment of relative whiteness $\rangle$, parallel test 4 times, and average the results.

\subsubsection{Breaking Strength Test}

Reference to standard GB/T 3923.1-2013《Textiles-Tensile properties of fabrics Part 1: Determination of breaking strength and breaking elongation using the strip method》, parallel test 3 times, and average the results.

\subsubsection{Vertical Combustibility Test}

Reference to standard GB/T 5455-2014《Textiles-Burning BehaviourDetermination of Burning Length,Afterglow Time and Afterflame Time of Vertically Oriented Specimens $\rangle$, ignition time was $3 \mathrm{~s}$, parallel test 3 times, and average the results.

B1 level: burning length less than $15 \mathrm{~cm}$, Afterflame Time less than $5 \mathrm{~s}$, Afterglow Time less than $5 \mathrm{~s}$;

B2 level: burning length less than $20 \mathrm{~cm}$, Afterflame Time less than $10 \mathrm{~s}$, Afterglow Time less than $10 \mathrm{~s}$.

\subsubsection{IR analysis}

Used Fourier infrared spectrometer by using $\mathrm{KBr}$ pellets, and the scan range was $4000 \sim 400 \mathrm{~cm}^{-1}$.

\subsubsection{TG analysis}

Synchronous thermogravimetric analyzer at a heating rate of $10^{\circ} \mathrm{C} / \mathrm{min}$, over the temperature range of $60^{\circ} \mathrm{C} \sim 600^{\circ} \mathrm{C}$, under a nitrogen atmosphere.

\section{RESULTS AND DISCUSSION}

\subsection{Flame retardant finishing process optimization}

\subsubsection{Dosage of finishing agent}

Flame retardants were prepared according to the better conditions determined above and different concentration finishing agents were prepared. The acrylic fabric was treated by padding and baking. The effect of the amount of finishing agent on the flame retardantcy, whiteness and breaking strength of acrylic fabric was investigated at $80^{\circ} \mathrm{C}$ for $5 \mathrm{~min}$. The results were shown in Table 1.

Table 1: Effect of finishing agent dosage on flame retardance, whiteness and breaking strength of acrylic fabrics.

\begin{tabular}{|c|c|c|c|c|c|c|}
\hline $\begin{array}{ll}\text { Dosage } & \text { of } \\
\text { finishing } & \\
\text { agent }(\mathrm{g} / \mathrm{L}) & \end{array}$ & $\begin{array}{l}\text { Afterflame Time } \\
\text { (s) }\end{array}$ & $\begin{array}{l}\text { Afterglow } \\
\text { (s) }\end{array}$ & Time & $\begin{array}{l}\text { Damaged Length } \\
(\mathrm{cm})\end{array}$ & Whiteness & $\begin{array}{l}\text { Breaking } \\
\text { Strength(N) }\end{array}$ \\
\hline 0 & 47.10 & 0.07 & & 30.0 & 82.8 & 1975.3 \\
\hline 50 & 58.31 & 0.07 & & 30.0 & 80.6 & 986.8 \\
\hline 100 & 34.95 & 0.07 & & 16.0 & 79.0 & 983.8 \\
\hline 150 & 29.50 & 0.07 & & 11.8 & 79.3 & 964.6 \\
\hline 200 & 0.98 & 0.07 & & 5.1 & 78.5 & 959.8 \\
\hline 250 & 0.85 & 0.07 & & 4.8 & 76.4 & 949.2 \\
\hline 300 & 0.079 & 0.07 & & 3.8 & 76.3 & 940.2 \\
\hline
\end{tabular}

From table 1, we can see that with the increase of finishing agent dosage, the flame retardance effect of acrylic fabric was obviously improved, and the whiteness and breaking strength are decreasing. Compared with the untreated acrylic fabric, the whiteness of flame retardant polyacrylonitrile fiber decreased slightly, and the breaking strength decreased significantly. When the dosage of the finishing agent reaches $200 \mathrm{~g} / \mathrm{L}$ and above, the flame-retardant efficiency of polyacrylonitrile fiber can reach B1 level. At the same time, the fabric also has better whiteness and higher breaking strength. Therefore, the optimal dosage of the finishing agent was determined to be $200 \mathrm{~g} / \mathrm{L}$.

\subsubsection{Baking temperature}

The effects of baking temperature on the flame-retardant efficiency, whiteness, and breaking strength of acrylic fabrics were investigated under the conditions of $200 \mathrm{~g} / \mathrm{L}$ finishing agent, 3 min pre-baking at $80{ }^{\circ} \mathrm{C}$, and 2 min baking at different temperatures. The results are shown in Table 2. 
Table 2: Results of baking temperature on flame retardant, breaking strength, whiteness of acrylic fabrics

\begin{tabular}{|c|c|c|c|c|c|}
\hline $\begin{array}{l}\text { Baking } \\
\text { Temperature }\left({ }^{\circ} \mathrm{C}\right)\end{array}$ & $\begin{array}{l}\text { Afterflame Time } \\
\text { (s) }\end{array}$ & Afterglow Time (s) & $\begin{array}{l}\text { Damaged Length } \\
(\mathrm{cm})\end{array}$ & Whiteness & $\begin{array}{l}\text { Breaking } \\
\text { Strength(N) }\end{array}$ \\
\hline 80 & 0.98 & 0.07 & 5.1 & 78.5 & 873.1 \\
\hline 90 & 8.41 & 0.07 & 6.6 & 78.8 & 891.6 \\
\hline 100 & 1.95 & 0.07 & 4.9 & 78.1 & 918.5 \\
\hline 110 & 3.40 & 0.07 & 5.3 & 78.1 & 920.7 \\
\hline 120 & 13.34 & 0.07 & 9.1 & 75.5 & 928.0 \\
\hline
\end{tabular}

From Table 2, it can be seen that with the baking temperature increases, the flame-retardant efficiency of the acrylic fabric becomes worse, the whiteness decreases slightly, and the breaking strength increases. When the baking temperature was $90^{\circ} \mathrm{C}$, the acrylic fabric becomes soft, the flame-retardant efficiency was obviously deteriorated, the after flame time was greatly increased, and the damaged char length was increased. The possible reason was that the glass transition temperature of the polyacrylonitrile fiber was about $90^{\circ} \mathrm{C}$. At this time, the polyacrylonitrile polymer segment was loosened and the material properties are mutated. Considering comprehensively, the optimal baking temperature was $80^{\circ} \mathrm{C}$.

\subsubsection{Baking time}

The effects of baking time (total length of time) on the flame-retardant efficiency, whiteness, and breaking strength of acrylic fabrics were investigated under the conditions of $200 \mathrm{~g} / \mathrm{L}$ of finishing agent and baking temperature of $80^{\circ} \mathrm{C}$. The results are shown in Table 3 .

Table 3: Results of Baking time on flame retardant, breaking strength, whiteness of cotton fabrics.

\begin{tabular}{|lllllll|}
\hline $\begin{array}{l}\text { Baking } \\
\text { Time(min) }\end{array}$ & $\begin{array}{l}\text { Afterflame } \\
(\mathrm{s})\end{array}$ & $\begin{array}{l}\text { Time } \\
\text { 3 }\end{array}$ & $\begin{array}{l}\text { Afterglow } \\
(\mathrm{s})\end{array}$ & $\begin{array}{l}\text { Time } \\
(\mathrm{cm})\end{array}$ & $\begin{array}{l}\text { Damaged Length } \\
\text { Whiteness }\end{array}$ & $\begin{array}{l}\text { Breaking } \\
\text { Strength(N) }\end{array}$ \\
5 & 2.13 & 0.07 & 4.8 & 79.1 & 942.4 \\
7 & 2.29 & 0.07 & 5.3 & 79.0 & 934.5 \\
9 & 2.06 & 0.07 & 4.9 & 79.1 & 1163.9 \\
11 & 3.84 & 0.07 & 4.9 & 78.5 & 1915.5 \\
\hline
\end{tabular}

From Table 3, it can be seen that with the extension of the baking time, the flame-retardant efficiency of the acrylic fabric has not changed much, reaching B1 level; the whiteness has not changed significantly; the breaking strength has increased significantly. Considering that the long baking time affects the production efficiency and causes energy waste, the baking time was selected as $3 \mathrm{~min}$.

\subsection{TG analysis}

Under the condition of $200 \mathrm{~g} / \mathrm{L}$ of finishing agent and baking at $80^{\circ} \mathrm{C}$ for 11 min, flame-retarded polyacrylonitrile fiber was obtained. The untreated polyacrylonitrile fiber and flame-retarded polyacrylonitrile fiber were taken for thermogravimetry under $\mathrm{N}_{2}$ atmosphere. The TG chart drawn from the test data was shown in Figure 1.

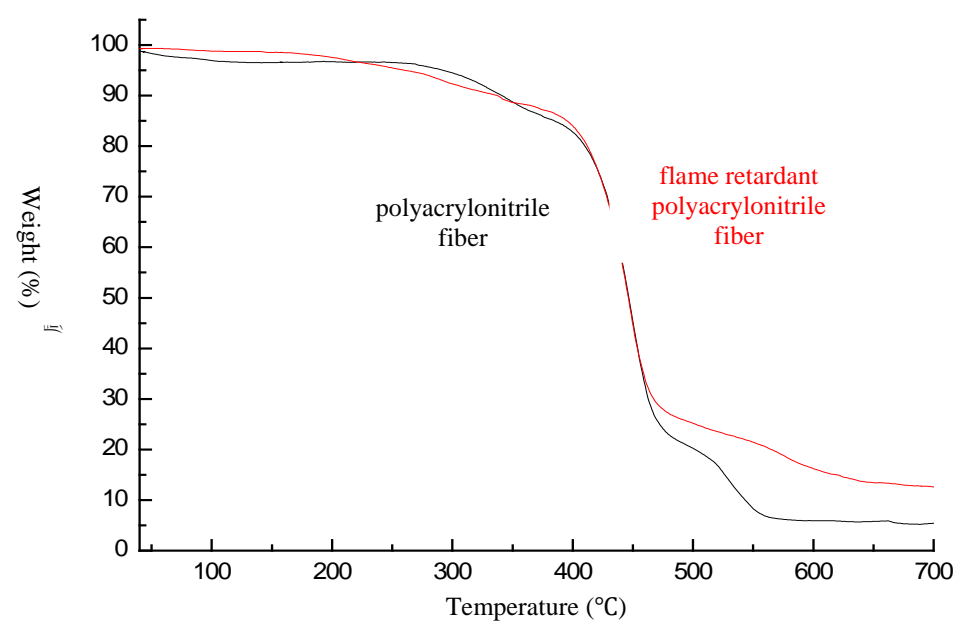

Figure 1: TG curve of ordinary acrylic and flame retardant polyacrylonitrile fiber

From Figure 1, we can see that the initial decomposition temperature decomposition rate (TG curve slope) and residual carbon content of polyacrylonitrile fiber have significant changes before and after flame retardancy. According to the data of table 4 and Figure 1, it can be seen that the thermal decomposition of the flame retardant polyacrylonitrile fiber was earlier than that of the untreated polyacrylonitrile fiber, and the decomposition rate was slowed down, and the amount of carbon residue was significantly improved.

Table 4: TG curve partial data

\begin{tabular}{|lll|}
\hline Project & Ordinary polyacrylonitrile fiber & Flame retardant polyacrylonitrile fiber \\
\hline Temperature at $5 \%$ weight $\operatorname{loss}\left({ }^{\circ} \mathrm{C}\right)$ & 337 & 167 \\
Temperature at $50 \%$ weight $\operatorname{loss}\left({ }^{\circ} \mathrm{C}\right)$ & 429 & 417 \\
$\begin{array}{l}\text { The amount of carbon residue at } 500 \\
{ }^{\circ} \mathrm{C}(\%)\end{array}$ & 13.4 & 17.9 \\
$\begin{array}{l}\text { The amount of carbon residue at } 700 \\
{ }^{\circ} \mathrm{C}(\%)\end{array}$ & 9.3 & 15.8 \\
\hline
\end{tabular}




\subsection{Comparison of flame retardant efficiency}

The untreated polyacrylonitrile fiber and the flame-retardant polyacrylonitrile fiber were respectively subjected to the vertical combustion test, at this time, observe the combustion phenomenon and the combustion effect was compared. The results are shown in Figure 2.
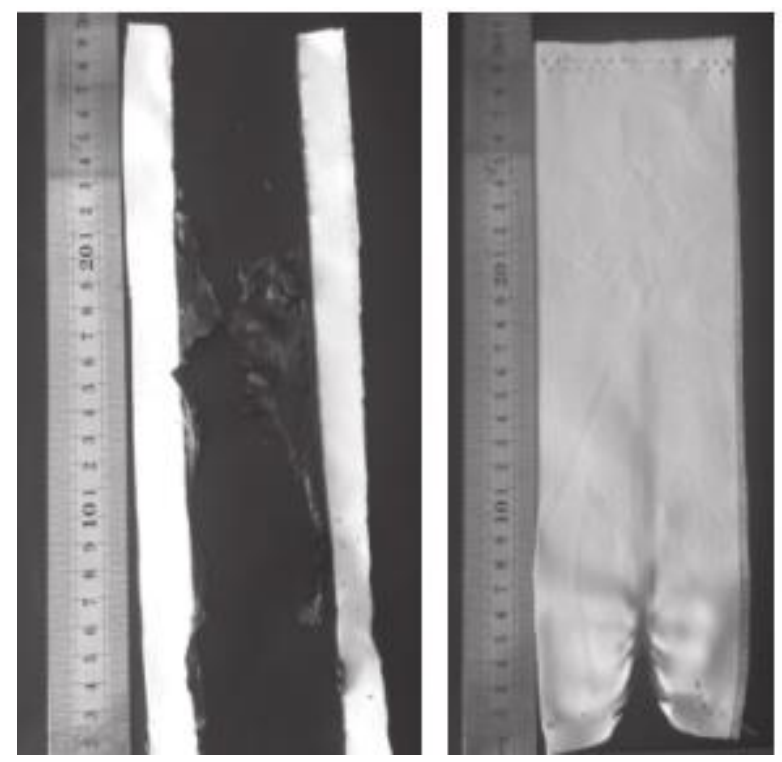

Figure 2: Combustion effect of untreated polyacrylonitrile fiber and flame retardant polyacrylonitrile fiber

It can be seen from Figure 2, the untreated polyacrylonitrile fiber was ignited with the quickly molten and burned, and the flame spread quickly, with a large number of black smoke and blacker residue; after the flame retardant polyacrylonitrile fiber was ignited, the flame was briefly burned and extinguished, the smoke was less, the combustion part had molten, a small amount of black residue, and the flame-retardant efficiency was obvious.

\section{SUMMARY}

(1) Under the conditions of $200 \mathrm{~g} / \mathrm{L}$ of finishing agent and $3 \mathrm{~min}$ for baking at $80^{\circ} \mathrm{C}$, the flame-retardant efficiency of the acrylic fabric can reach the national standard B1, the whiteness of the fabric decreases slightly and the breaking strength decreases obviously, but it still remains at a high value. (2) TG and combustion tests show that flame retardants have significant Flame Retardancy for polyacrylonitrile fibers from microcosmic and macro perspectives.

\section{REFERENCES}

[1] Xiang, Y., Wanli, Z., Xiangsen, Z. 2015. Preparation, flame retardancy and thermal degradation behaviors of polyacrylonitrile fibers modified with diethylenetriamine and zinc ions. Journal of Thermal Analysis and Calorimetry, 124, 719-718.

[2] Ruixue, Z., Xudong, Z., Zhongmin, G. 2017. Influence of Thermal Temperature on the Structure and Sealed Micropores of Stabilized Polyacrylonitrile Fibers. Chemical Research in Chinese Universities, 33 (2), 312-317.

[3] Gu, J.W., Dong, S.L., Kong, J. 2007. Study on preparation and fireretardant mechanism analysis of intumescent flame-retardant coatings. Surface \& Coatings Technology, 201 (18), 7835-7841.

[4] Mauerer, 0. 2005. New reactive, halogen-free flame-retardant system for epoxy resins. Polymer Degradation and Stability, 88 (1), 70-73.

[5] Zhao, C.S., Huang, F.L., Wang, Y.Z. 2008. A novel halogen-free flame retardant for glass-fiber-reinforced poly-(ethylene terephthalate). Polymer Degradation \& Stability, 93 (6), 1188-1193.

[6] Li, Q., Jiang, P., Wei, P. 2006. Synthesis, characteristic, and application of new flame retardant containing phosphorus, nitrogen, and silicon. Polymer Engineering and Science, 46 (3), 344-350.

[7] Chen, X., Hu, Y., Song, L. 2008. Thermal behaviors of a novel uv cured flame retardant coatings containing phosphorus, nitrogen and silicon. Polymer Engineering and Science, 48 (1), 116-123.

[8] Chen, Y., Peng, H., Li, J. 2014. A novel flame retardant containing phosphorus, nitrogen, and sulfur. Journal of Thermal Analysis and Calorimetry, 115 (2), 1639-1649.

[9] Li, Q., Jiang, P., Tang, X. 2010. Synergistic effect of phosphorus, nitrogen, and silicon on flame-retardant properties and char yield in polypropylene. Journal of Applied Polymer Science, 96 (3), 854-860.

[10] Li, J., Zhu, H., Tian, X. 2011. Thermal degradation behaviors of phosphorus-silicon synergistic flame-retardant copolyester. Journal of Applied Polymer Science, 122 (3), 1993-2003. 